\title{
The Jaffna Medical Journal as a forum for undergraduate research
}

\author{
Sarangan Ketheesan ${ }^{1}$, Rajaratnam Natkunam ${ }^{1}$, Natkunam Ketheesan ${ }^{1}$ \\ ${ }^{1}$ School of Science and Technology, University of New England, Australia
}

\begin{abstract}
It is unfortunate that over the last 65 years many factors have contributed to the sporadic publication of the Jaffna Medical Journal (JMJ). To sustain publication as a regular periodical, it is important to explore avenues to increase the number of submissions of high-quality manuscripts. One untapped source that could significantly enhance the number of submissions to JMJ are manuscripts arising from research undertaken by undergraduate students. To enable such students to produce high quality manuscripts from the work they carry out, students have to be adequately trained and mentored. We are of the view that if appropriate training is provided for undergraduates it will not only help JMJ in the short-term but also nurture the aspirations of future clinicians and researchers who have an interest in inquiry. Moreover, such an investment in student training and capacity building will ensure the future continuity of the Journal.
\end{abstract}

(Key words: medical education, medical research, undergraduate research, undergraduate publications)

\section{Introduction}

It is a matter of pride that the first Medical School to teach Scientific or Allopathic Medicine in Sri Lanka was established as long ago as 1848 at Manipay in Jaffna. Named the Green Memorial Hospital in honour of its founder Dr Samuel Fisk Green, a medical missionary and graduate of the College of Physicians and Surgeons in New York City; its graduates served in all parts of Sri Lanka and also in India during the 19th century. The Jaffna Medical Association was founded almost a century later and produced its first publication, "The Jaffna Medical Journal" (JMJ) in 1958. It is unfortunate that over the years many factors have conspired to prevent the publication of the Journal on a regular basis. However, the establishment of the Medical Faculty in the University of Jaffna in 1978 and with the Jaffna Hospital being designated as a "Teaching Hospital" with a permanent Academic and Specialist staff should enhance and foster its uninterrupted publication.

\section{Medical research and medical training}

For several years, students undertaking undergraduate degrees in medicine and health related disciplines at the University of Jaffna have contributed to research. Undergraduate students have carried out research as either part of their pre-clinical subject requirements or on an entirely voluntary basis. Manuscripts arising from such research have been sporadically published in peer reviewed journals. $(1,2)$ Undergraduates can be an invaluable asset to conduct high quality research if they are trained and mentored appropriately. Several professional bodies and organisations have established journals dedicated to publishing peer-reviewed literature reviews, meta-analyses, research articles and case reports authored by students. (3-5) JMJ could adopt a similar approach by including a dedicated section in every issue of the Journal devoted to contributions authored by students. Having a student member in the JMJ Editorial Board will further facilitate training for students inclined to develop academic credentials.

\section{Medical and research training-an international comparison and perspective}

During the three generations since the JMJ was first published, medical education and pedagogical practices have changed. Many would argue that the current medical curricula are unrecognisable from what was taught three generations ago. Certainly, rapid advances in gene therapy including Corresponding Author: Professor Natkunam Ketheesan Email: nkethees@une.edu.au, (D) https://orcid.org/0000-0002-4870-706X This is an open-access article distributed under the terms of the Creative Commons Attribution 4.0 International License, which permits unrestricted use, distribution and reproduction in any medium provided the original author and source are credited 
CRISPR gene editing procedures, oncology, neurosciences, immunotherapy, microbiome research, microsurgical techniques and concepts in personalised medicine have made it necessary to include these sciences into pre and paraclinical areas of the curriculum. Although, inclusion of these subjects has come at a cost of more traditional skills in anatomical dissection and the ability to carry out basic biochemical tests, the current curricula have to provide the foundation for future practitioners to be able to work in different environments for the often-five-decade duration of their careers. The use of computers, computer simulation, telemedicine, fibre optics, imaging modalities, in silico experiments, mathematical modelling and prediction algorithms have changed how medicine is taught in many medical schools. Today we deliver course material with more emphasis on self-directed and problem-based learning, making the course more accessible to larger cohort of students as opposed to didactic teaching and small group learning. However, the fundamental aspects such as clinical observations, evidence-based practice and holistic approach to treatment have been passed on for generations and remain the cornerstone in medical education, albeit now with new nomenclatures and classifications.

One method of increasing rates of student research output, seen across many countries, is the development of intercalated research and medical degrees. Clinicians should not leave biomedical discoveries to scientists alone. (6-8) Several well established and newly formed medical courses overseas offer intercalated MBBS/PhD, BSc/MBBS degrees or the equivalent. The structure of these intercalated degrees allows for a substantial body of publishable research to be completed between preclinical and clinical components of the MBBS or MD and relies on formal mentoring of students in research methods and writing. It has been shown that such programmes are a useful addition to the conventional medical undergraduate programmes in terms of superior student performance, skills development and may also positively contribute to subsequent careers. (9) Clinical research and publishing research findings are now prerequisites that are found in most position descriptions for senior staff interested in securing appointments in

Vol.31, No.1, July 2019 teaching hospitals and institutions associated with medical training. Whilst restructuring the medical curriculum to allow for intercalated degrees may not be a practical solution to the shortage of student research output in the short-term in Sri Lanka, it is certainly a prospect which should be considered as a long-term ambition.

\section{Process of lifelong learning}

The exponential growth of knowledge poses a realistic challenge in medical education and practice. Several factors currently contribute to the rapid growth of medical knowledge. The amount of information generated by computers will soon outstrip what humans are able to generate. Mega data and modern data analytics having already impacted on how we perceive spread of infectious diseases and the impact of risk factors on the progression of chronic diseases. We increasingly rely on inventions and innovations of analytical, imaging and therapeutic tools to carry out our daily professional duties. As never seen before, a knowledge-sharing society consisting of multidisciplinary and multinational teams has emerged creating opportunities for discoveries to be shared, enhancing rapid development. As a result, the exponential growth of knowledge has in itself caused a major impact on society. Compounding to this challenge is the realisation as to how long knowledge remains current.

Knowledge we gained at school, in universities, in our intern years or even the last workshop we attended, may be of less value now than when we first learned it. Those predominantly working in areas related to sciences and medicine must acknowledged this reality and encourage students to recognise the value and need to constantly update and to practice the concept of lifelong learning and teaching. It is prudent to remember the words attributed to American writer Alvin Toffler, who is known for his work on modern technologies and their impact on cultures: "the illiterate of the $21^{\text {st }}$ century will not be those who cannot read and write, but those who cannot learn, unlearn, and relearn". (10) All members of the medical field have a lot to learn from each other and even medical students can teach their peers and in some instances their teachers! Hence, it is vital to encourage the next 
generation of the medical community to be trained in undertaking research as a means of not only staying current with an ever-increasing literature base but also to bring fresh and innovative ideas.

\section{Formal mentoring of students in research and publishing}

One of the major tenets of medical education - in both Eastern and Western medical training dating back to centuries - is the importance of mentorship to ensure the succession and sustainability of the medical profession. (11) The fact that this principle has enabled such a tradition to have existed for successive millennia is reason enough for the JMJ to advocate for a greater level of research mentorship among medical practitioners, academics and students. Providing incentives and mentorship for students to publish their research can act to create a sustainable culture of research excellence. Formalised incentives to increase the publication rate of students could include small grants for students to undertake research projects under a designated mentor with the view of publishing their findings. Such incentives would provide a platform for academics and clinicians to equip students to carry out and publish high-quality research in this Journal (and indeed other peer-reviewed journals), whilst simultaneously increasing their own research output and credibility.

Formalised research mentorship and platforms for publication of research would allow for the academic growth of students, greater output of publications by the region's health services and educational intuitions, and possibly the eventual development of centres of research excellence in the region. These have been largely unfeasible in the past due to an array of social circumstances and longstanding civil conflict. There is a need for medical educators to encourage students to conduct research and provide counsel on the attitudes required for them to succeed in a research environment. (12) This is particularly important for those future clinicians who plan to complete part of their specialist training in institutions overseas where research is a prerequisite for career progression. Many members of the JMJ Editorial Board hold posts at the Jaffna Teaching Hospital and the University of Jaffna and thus, -28 - have the propensity and authority to catalyse the development of formalised mentoring programmes for undergraduates providing avenues to publish research findings.

\section{Futureproofing the JMJ through ungraduated research}

What better way is there for a journal such as the JMJ than to support and mentor future clinicians and biomedical researchers, than providing a forum to publish quality student research findings? Such an approach may also overcome the issues related to the irregularity of publication faced by the Journal over the last 65 years.

\section{References}

1. Mahalingam $U$, Thirunavukarasu $\mathrm{K}$, Murugananthan K. Methicillin resistant Staphylococcus aureus among nurses in a tertiary care hospital in northern Sri Lanka. Ceylon Med J. 2014; 59(2):63-65

2. Piratheepkumar $\mathrm{V}$, Kulendran $\mathrm{S}$, Nadarajah $S$, Murugananthan K. Hepatitis B vaccine immunogenicity among nurses of a hospital. Ceylon Med J. 2014; 59(2):59-60

3. American Medical Student Research Journal; https://www.amsrj.org/

4. Australian Medical Student Journal: http:// www.amsj.org/

5. Student BMJ: http://student.bmj.com/

6. Filewod NC, Batt J, Kapus A, Szaszi K, Fairn GD, Slutsky AS, Lee WL. Should basic science matter to clinicians? Lancet 2018; 391(10119):410-412

7. Brown NJ. Developing Physician-Scientists. Circ Res. 2018; 123:645-647

8. Armstrong K, Ranganathan R, Fishman M. Toward a culture of scientific inquiry - the role of medical teaching services. $N$ Engl J Med. 2018; 4;378(1):1-3

9. Jones M, Hutt $P$, Eastwood S, Singh S. Impact of an intercalated BSc on medical student

Jaffna Medical Journal 
performance and careers: a BEME systematic review: BEME Guide No. 28. Med Teach. 2013; 35(10):e1493-510

10. Learning solutions: https://www.learning solutionsmag.com/articles/2468/
11. Sathiadas MG. Role modelling in medicine. Jaffna Medical Journal 2018; 30(1): 1-2

12. Mabvuure NT. Twelve tips for introducing students to research and publishing: a medical student's perspective. Med Teach. 2012; 34(9):705-709 